\title{
Hygrothermal performance of timber frame walls with brick veneer cladding: a parameter analysis
}

\author{
Michiel Vanpachtenbeke ${ }^{1,2, *}$, Jan Van den Bulcke ${ }^{2}$, Joris Van Acker ${ }^{2}$, and Staf Roels ${ }^{1}$ \\ ${ }^{1}$ KU Leuven, Department of Civil Engineering, Building Physics Section, Kasteelpark Arenberg 40 - box 2447, BE-3001 Heverlee, \\ Belgium \\ ${ }^{2}$ UGent, Department of Environment, Laboratory of Wood Technology (UGent-Woodlab), Coupure Links 653, BE-9000 Gent, \\ Belgium
}

\begin{abstract}
To meet the increasingly stringent energy efficiency requirements, the market share of timber frame houses is steadily growing across Europe. Timber frame walls in Belgium are typically combined with a brick veneer cladding, which has a high buffer capacity for wind driven rain and a relative low cavity ventilation rate. Consequently, moisture levels inside the cavity may become high, which might lead to an inward vapour flow and an elevated moisture content in the inner part of the wall. In combination with a moisture sensitive timber frame inner wall, this could result in an increased risk of fungal growth. Therefore, the aim of the current paper is to study the hygrothermal performance of timber frame walls with brick veneer cladding in a moderate sea climate. To do so, a field study on two typical timber frame walls with brick veneer cladding is conducted. The field study specifically focuses on the contradictory criterion for the vapour diffusion resistance of the wind barrier for summer and winter conditions. The data of the insitu measuring campaign indicates that the differences between set-ups with wind barriers with different vapour diffusion resistance is rather limited. In addition, a parameter analysis is conducted using a numerical model. The parameter analysis indicates an increased mould growth risk due to the brick veneer cladding and the importance of providing hygroscopic moisture buffer capacity inside the wall.
\end{abstract}

\section{Introduction}

Building enclosures protect the indoor environment from exterior environmental loads. The control of in- and outward heat and mass transport is an essential aspect herein. In order to reduce the risk of moisture related damage in the exterior building component, however, an effective moisture control strategy is crucial, especially in case of timber frame walls.

Several measures in building practice are taken to keep the moisture levels in a timber frame wall to an acceptable level. Today, it is common practice in Europe to provide a vapour barrier/retarder at the inside of a timber frame wall, while the layers to the outside have an increasing level of vapour permeability. This limits the risk of interstitial condensation in the outer layers of the wall due to an outward vapour flow. A rule of thumb suggests that the exterior sheathing is at least 5 times more vapour open than the interior sheathing [1]. BBRI [2], the Belgian Building Research Institute, recommends the interior sheathing to be 6 to 15 times more vapour tight than the exterior one. This design principle is obviously based on cold climates [3,4], not considering a possible inward vapour flow. In moderate European climates, however, mainly an outward vapour flow will take place through the building component in winter conditions, while in summer conditions solar driven inward vapour transport may occur. Hence, this leads to a contradictory criterion for the vapour diffusion resistance of the exterior and interior sheathing. If the timber frame wall is finished with a brick veneer cladding, which has a high buffer capacity for wind driven rain yet low cavity ventilation rates [5], solar driven inward vapour transport might become critical. Therefore, the aim of the present paper is to study the performance of a timber frame wall with brick veneer cladding. To do so, a field study on two typical timber frame walls with brick veneer cladding has been conducted. In addition, also numerical simulations have been performed to address the impact of different parameters.

\section{Field study}

This section discusses the in-situ measuring campaign on two timber frame walls with brick veneer cladding, also reported in [6,7]. First, an overview of the experimental set-up and material properties is given. Thereafter, the results of the in-situ measurements are discussed.

\subsection{Experimental set-up}

A long-term in-situ measuring campaign on two typical timber frame walls with brick veneer cladding has been

\footnotetext{
* Corresponding author: michiel.vanpachtenbeke@kuleuven.be
} 


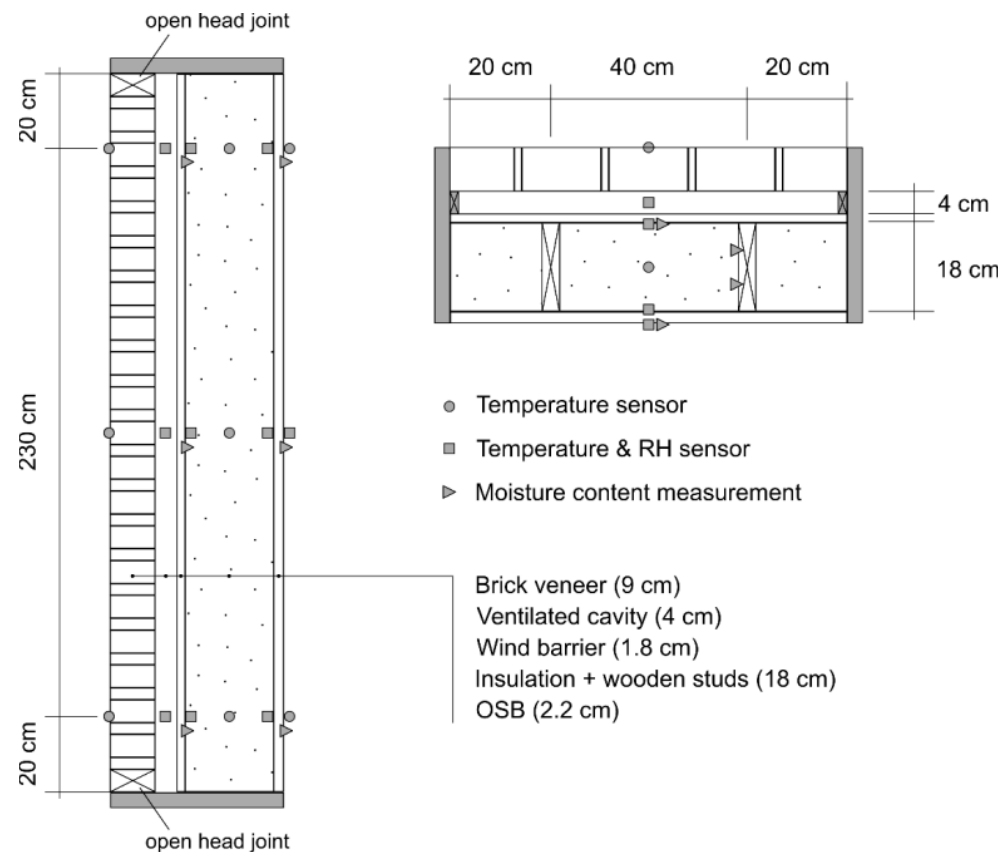

Fig. 1: Vertical and horizontal section of the timber frame test walls, showing the configuration and sensor positioning.

conducted in the VLIET test building of KU Leuven, Belgium. The VLIET-building is a full-scale outdoor test facility constructed to study the hygrothermal behaviour of building components under real weather conditions. A detailed description of the building can be found in [8]. Both walls are installed at the building's Southwest façade, which is in Belgium the dominant wind direction of wind driven rain and solar radiation. The general configuration and sensor positioning is presented in Figure 1. The walls are 2.7 meters high and 0.8-0.9 meters wide and consist of a brick veneer cladding ( 9 $\mathrm{cm})$, a ventilated cavity $(4 \mathrm{~cm})$, a wind barrier $(1.8 \mathrm{~cm})$, mineral wool insulation between wooden studs $(18 \mathrm{~cm})$ and an OSB board $(2.2 \mathrm{~cm})$ as vapour retarder and interior finishing layer. The two walls are identical, except for the type of wind barrier, which is discussed in '2.2. Material properties'. Scots pine wood (Pinus sylvestris L.) is used for the wooden studs, which have a width of $3.6 \mathrm{~cm}$. A grid of sensors measures the temperature and relative humidity at the different positions in the wall. The sensors are positioned at midheight as well as at $20 \mathrm{~cm}$ from the top and bottom of the wall. In addition, the outside climatic conditions are recorded by the building's weather station. These measurements include temperature, relative humidity, solar radiation, rain, wind speed and direction. The reader is referred to [9] for more details of the set-up and measurement equipment.

The measurements started in October 2015 and ended in January 2019. Initially, one open head joint (3.5 x 1.5 $\mathrm{cm}^{2}$ ) at the top and bottom of each wall was provided for cavity ventilation. On May 5, 2017, all open head joints were closed.

\subsection{Material properties}

Both walls are identical except for the type of wind barrier. In one set-up a vapour open bituminous impregnated wood fibre board $\left(\mathrm{Celit}^{\mathrm{a}}\right.$, referred to as 'open W(ind) B(arrier)') is used as wind barrier, whereas in the other set-up a more vapour tight wood fibre cement board (Duripanel ${ }^{\mathrm{b}}$, referred to as 'tight WB') is used. Figure 2 compares the equivalent water vapour diffusion air layer thickness $\left(\mathrm{s}_{\mathrm{d}}\right)$ of both wind barriers and the OSB. Furthermore, also the moisture storage capacities of both wind barriers are different, as illustrated by their sorption isotherms depicted in Figure 3. The tight WB has a significant higher moisture buffer capacity in the hygroscopic region compared to the open WB.

In addition, different laboratory experiments were carried out to obtain the moisture storage and transport properties of the applied brick. This revealed an average capillary saturation moisture content of $0.256 \mathrm{~m}^{3} / \mathrm{m}^{3}$ and an average capillary sorption coefficient of 0.258 $\mathrm{kg} / \mathrm{m}^{2} \mathrm{~s}^{1 / 2}$. More details on the material properties can be found in [9].

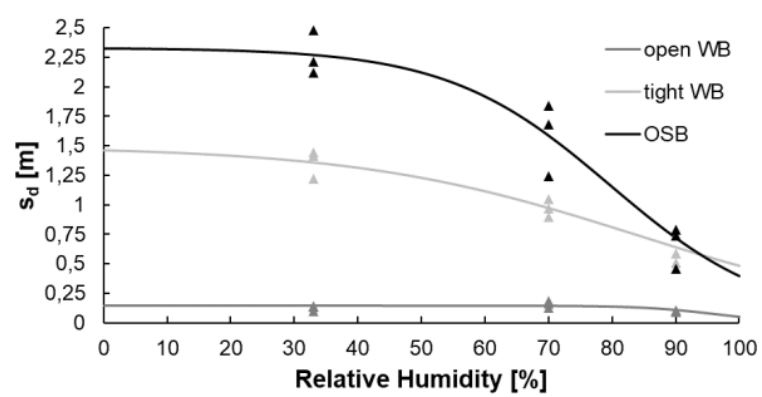

Fig. 2: The vapour diffusion resistance ( $\mathrm{s}_{\mathrm{d}}$-value) for the wind barriers and vapour retarder installed in the test walls.

\footnotetext{
a Isoproc Solutions. Celit 3D.

isoproc.be/nl/solutions/producten/detail/celit-3d/355

${ }^{\mathrm{b}}$ Siniat. Duripanel S3(B1).

siniat.be/nl-be/producten-en-

systemen/producten/platen/vezelcementplaat-duripanel
} 


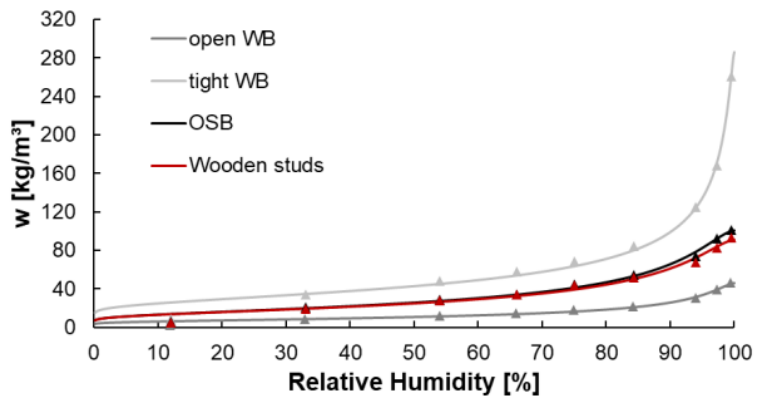

Fig. 3: Sorption isotherm fit (solid line) based on adsorption data (filled markers) of the different materials in the timber frame test walls

\subsection{In-situ results}

This subsection discusses the results of the in-situ measuring campaign of the two timber frame walls with brick veneer cladding. Focus is on the role of the vapour diffusion resistance of the in- and exterior sheathing. Therefore, the risk of interstitial condensation at the interface between insulation and wind barrier is assessed.

First, to get an idea of the vapour flow through the wall, Figure 4 compares the cavity vapour pressure (measured at the top on a 10-minute basis) to the indoor vapour pressure. For the studied timber frame walls with a brick veneer cladding in this measuring campaign, inward vapour transport is very common, even in winter conditions. Based on these data, conditions leading to an inward vapour flow occurred for both walls during approximately $40 \%$ of the time in 2016 when one open head joint at the top and bottom of the wall was provided.

\subsubsection{Interface insulation/wind barrier}

The interface between insulation and wind barrier is a potential condensation plane for outward vapour transport in winter conditions. Figure 5 presents for the winter (21 Dec - 21 Mar) of 2017: 1) the comparison of the indoor vapour pressure to the average cavity vapour pressure, and 2) the maximal measured relative humidity at the interface between mineral wool (MW) and wind barrier (WB) for the vapour open and tight set-up. Since the interface is at the cold side of the wall and the relative humidity inside the cavity is high during the winter period, the relative humidity at the interface is high as well. Nevertheless, opposed to the expectation that a vapour open wind barrier is much more beneficial in these conditions, the data demonstrates that the differences between both set-ups is rather limited. Moreover, the relative humidity at the interface between insulation and wind barrier for the vapour open set-up is even regularly higher compared to the vapour tight setup. This can be explained by the high vapour pressures inside the cavity of both walls. The cavity vapour pressure is often higher than the indoor vapour pressure, which in that case makes a more vapour tight wind barrier more beneficial to reduce the moisture levels at its interface with the insulation layer. Only in cold periods when the cavity vapour pressure drops to significantly lower values than the indoor vapour pressure during a longer period of time, the relative humidity of the vapour tight set-up exceeds the relative humidity of the vapour open set-up. It must be stated, however, that the vapour diffusion resistance of the tight WB is significantly lower in the higher RH-region than in the lower RH-region, as illustrated in Figure 2.

Finally, since the $\mathrm{RH}$ in the winter periods is constantly high, there is not much difference whether the cavity is ventilated or not.

\subsubsection{Interface insulation/vapour retarder}

In spring and summer conditions (21 March - 21 September), the interface between insulation and vapour retarder is a potential condensation plane for inward vapour transport. Figure 6 shows the hygrothermal conditions inside the cavity (average of top-bottom) and of the indoor environment, and the maximal measured relative humidity along the interface between insulation and vapour retarder (OSB) for the spring and summer of 2016. Due to a technical malfunctioning, the results are only shown until August. The peaks in relative humidity at the interface between insulation and vapour retarder are generally slightly higher for the vapour open set-up, but overall little difference can be noticed between the vapour open and vapour tight set-up. For both set-ups, the relative humidity at the interface between insulation and vapour retarder regularly exceeds $80 \%$, but always shortly. Moreover, the relative humidity does not reach condensation conditions.

When all open head joints are closed, still no problems with interstitial condensation are observed. The relative humidity generally stayed below $90 \%$ at the interface between insulation and vapour retarder. A possible explanation might be the buffer capacity in the wall.

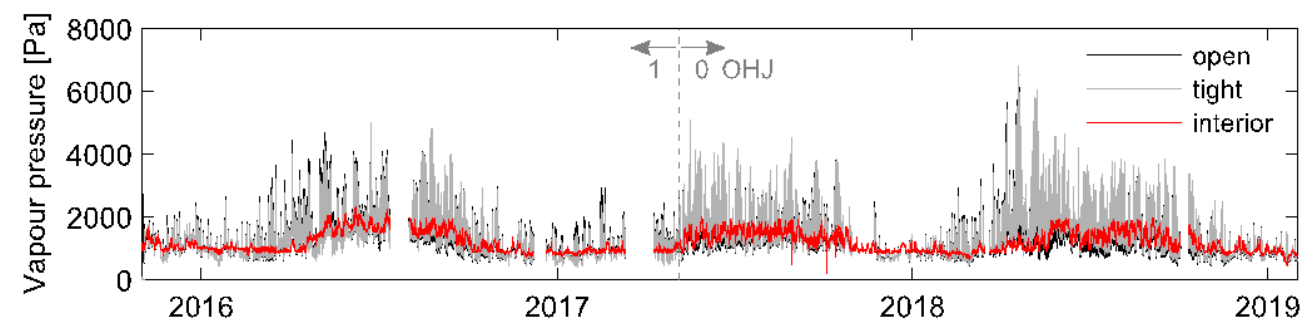

Fig. 4: Comparison between the in-situ measured vapour pressure inside the cavity of the vapour open/vapour tight set-up and the vapour pressure of the indoor environment from November 2015 until January 2019. 


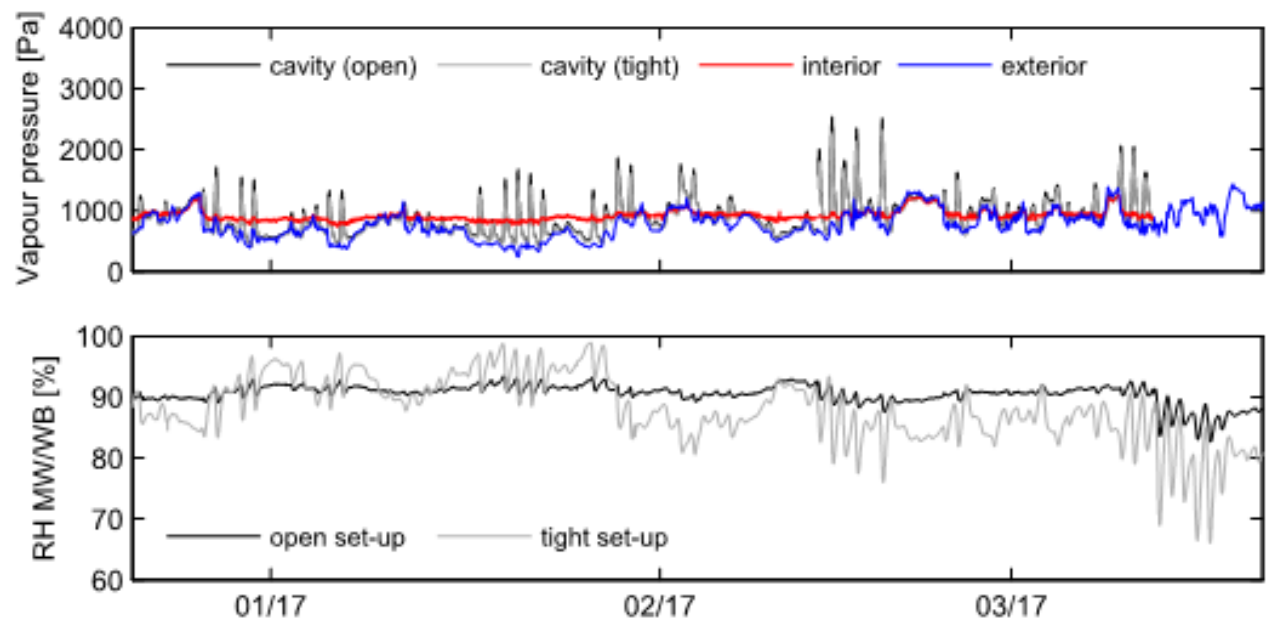

Fig. 5: Comparison of the in- and exterior vapour pressure to the average cavity vapour pressure and the maximal measured relative humidity at the interface between mineral wool (MW) and wind barrier (WB) for the winter of 2017.
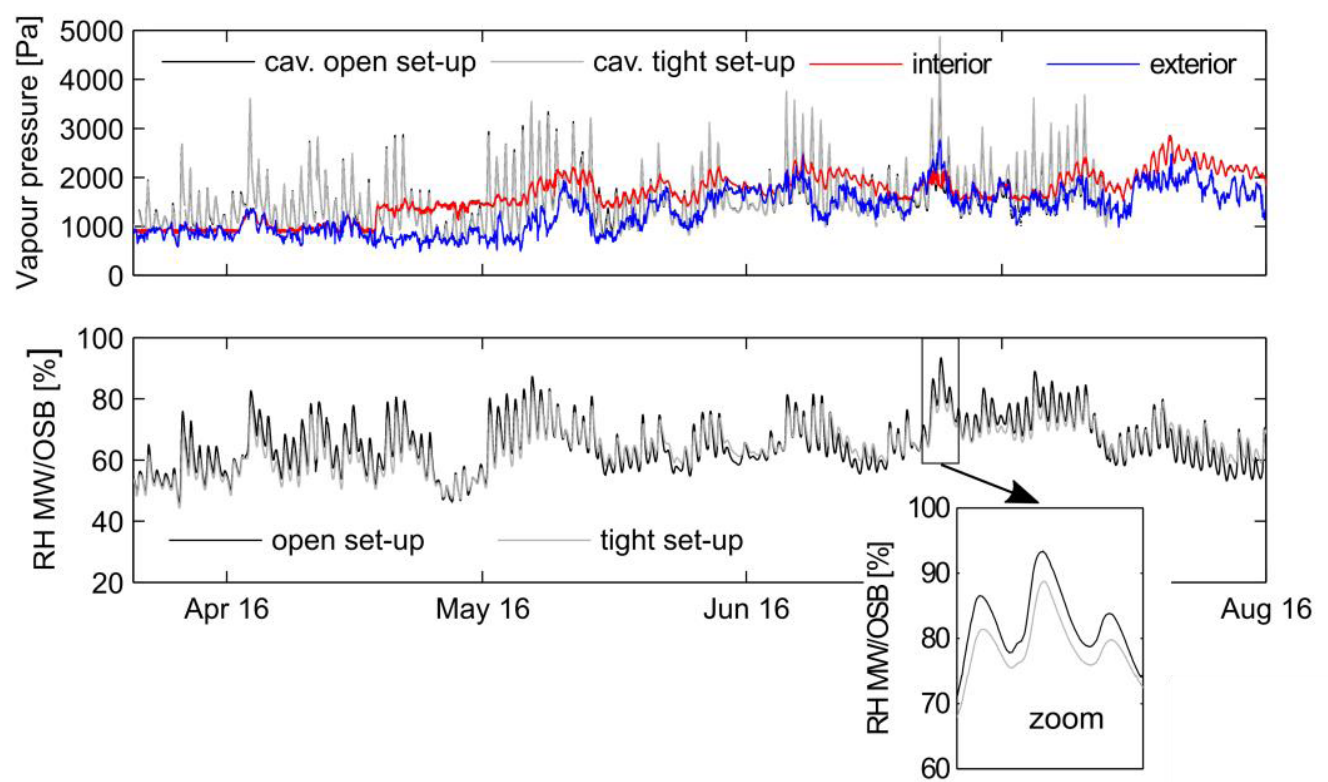

Fig. 6: Comparison of the in- and exterior vapour pressure to the average cavity vapour pressure and the maximal measured relative humidity at the interface between mineral wool (MW) and vapour retarder (OSB) for both set-ups during spring and summer of 2016.

\section{Numerical simulations}

In the previous section, the hygrothermal performance of timber frame walls finished with a brick veneer cladding has been assessed based on in-situ measurements. Consequently, conclusions only apply for the specific boundary conditions and the considered material properties in the in-situ measuring campaign. Therefore, in this section a small parameter analysis is conducted based on numerical simulations.

\subsection{Numerical model}

A 2D numerical model is created in the DELPHIN 5 software $[10,11]$ in accordance with the timber frame test walls of the in-situ measuring campaign. A 2Dvertical section of the wall is considered, containing a brick-mortar composite as outer leaf $(9 \mathrm{~cm})$, a ventilated cavity $(4 \mathrm{~cm})$, a wind barrier $(1.8 \mathrm{~cm})$, mineral wool insulation $(18 \mathrm{~cm})$ and OSB $(2.2 \mathrm{~cm})$ as interior vapour retarder. The open WB (see previous section) is provided as exterior sheathing for the reference simulation. In addition, the wall is extended with a service cavity of 5 $\mathrm{cm}$ and a gypsum board as interior finishing layer. The service cavity is insulated with mineral wool, and the gypsum board has an equivalent air layer thickness for water vapour diffusion equal to $0.12 \mathrm{~m}$. Also, a wooden beam, which was not provided in the test walls, at the top and bottom of the wall between wind barrier and OSB is added to the grid. Furthermore, one open head joint at the top and bottom of the wall is considered in order to create cavity ventilation. Cavity ventilation is modelled by means of the hydraulic network approach. Air looping in the mineral wool layer is not included since it does not significantly affect the simulation 
results [9]. A solar absorption coefficient of 0.6 is applied to the beige-yellow brick veneer cladding. Finally, the Test Reference Year of Uccle, retrieved from METEONORM $^{\mathrm{c}}$, is imposed as outside boundary condition. The interior climate boundary conditions are based on standard NBN EN 15026, using the "normal occupancy' condition for indoor RH. The reader is referred to [9] for more details and the verification of the numerical model.

In the following subsections, the impact of the moisture buffer capacity and vapour diffusion resistance of the wind barrier and vapour retarder is studied. Also, the impact of cavity ventilation on the performance of the wall is investigated. The presented simulation outcomes are the result of a two-year simulation with cyclic, yearly boundary conditions. Only the performance of the wall during the second year will be considered in this paper.

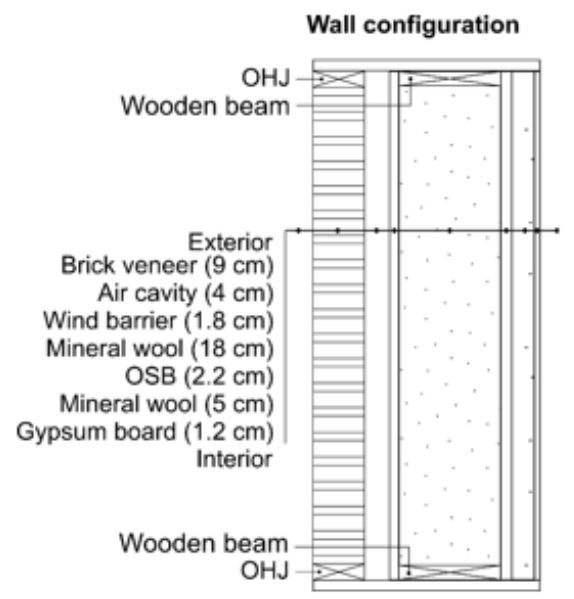

Fig. 7: Wall configuration of the timber frame walls in the numerical model.

The performance of the timber frame walls in the following simulations is assessed based on the risk of mould growth and wood decay. To assess the mould growth risk, the updated VTT model [12] is used. The 'sensitive' class is considered for OSB and the 'medium resistant' class for the open WB. A mould index of 3 is considered as limit state criterion. Finally, to assess the risk of wood decay, it is investigated if interstitial condensation and run-off occurs at one of the interfaces inside the wall.

\subsubsection{Impact of moisture buffer capacity}

In a first simulation the wind barrier is replaced by a foil with an equivalent air layer thickness for water vapour diffusion $\left(\mathrm{s}_{\mathrm{d}}\right.$ value) equal to $0.09 \mathrm{~m}$ [13]. It must be stated that for the simulations in this section which include a foil as wind barrier, long wave radiation between the cavity surfaces is omitted due to numerical stability problems. Consequently, the results of those simulations regarding the relative humidity at the interface between mineral wool and wind barrier will be

${ }^{c}$ www.meteonorm.be too optimistic in winter conditions. In a second simulation, compared to the reference simulation, the OSB is replaced by a foil with a similar, yet constant $s_{d}$ value of $2 \mathrm{~m}$. The foils in both simulations have no buffer capacity. Figure 8a presents the mould risk at the top (red), middle (middle) and bottom (green) of the interface between mineral wool and wind barrier, and between mineral wool and OSB for the reference simulation (x) and the simulations with a foil replacing the wind barrier $(\Delta)$ or OSB $(\mathrm{O})$. The foils are considered very resistant to mould growth, and hence the mould risk at their surface is not included $(\mathrm{M}=0)$. In addition, Figure $8 \mathrm{~b}$ presents the mould risk for the wooden beam at the top (red) and bottom (blue) of the wall for the three different simulations. The mould risk inside the construction is quasi identical to the reference simulation.
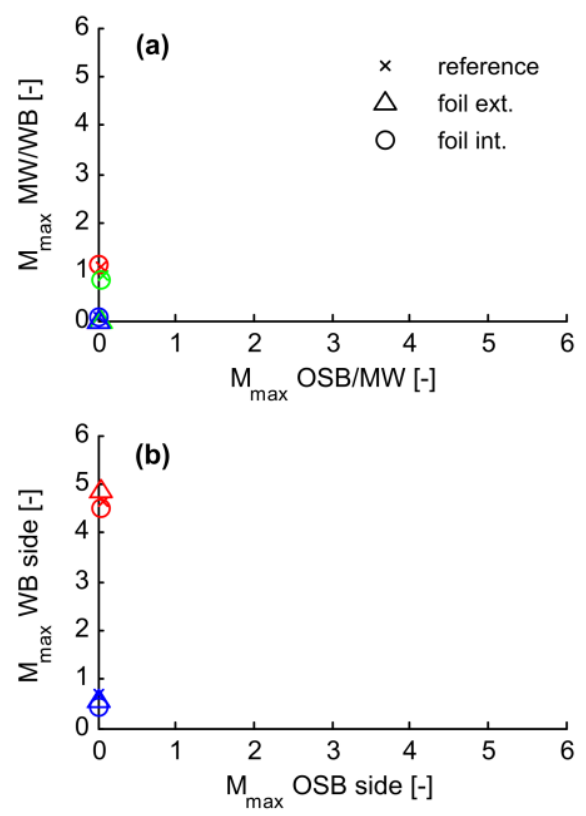

Fig. 8: For the reference simulation (x), the simulation with a foil as wind barrier $(\Delta)$, and the simulation with a foil as vapour barrier (o): a) the maximal mould index at the top (red), middle (green) and bottom (blue) of the interface between mineral wool and in- and exterior sheathing; and b) the maximal mould index for the top (red) and bottom (blue) wooden beam at the side of the wind barrier (WB) and OSB.

In contrast, larger differences are obtained for the maximal $\mathrm{RH}$ at the interface between mineral wool and wind barrier, and between mineral wool and vapour retarder, as shown in Figure 9. Applying a foil instead of a moisture buffering material as wind barrier or vapour retarder leads to a saturated humidity level, and hence a condensation risk at the considered interface. Nevertheless, the maximal accumulated condensation at both interfaces $\left(\mathrm{AC}_{\max }\right)$ remains lower than the threshold value of $0.1 \mathrm{~kg} / \mathrm{m}^{2}[13,14]$. It must be stated again that the accumulated condensation at the interface between mineral wool and wind barrier might be underestimated by not including long wave radiation between the cavity surfaces. Based on these results, run-off is not expected and hence, wood decay is unlikely to occur inside the construction. Nevertheless, the benefits of using 
hygroscopic materials as wind barrier and/or vapour retarder to lower the $\mathrm{RH}-$ level at its surface are clear.

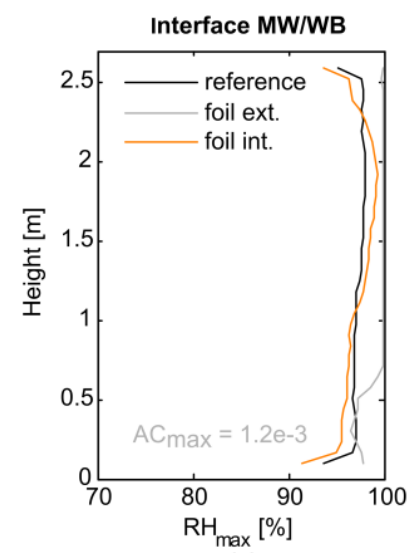

(a)

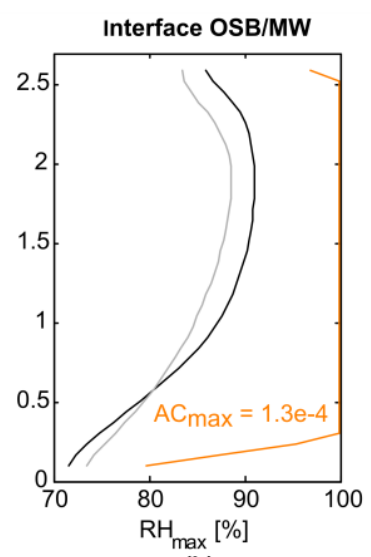

(b)
Fig. 9: Maximal RH at the interface between a) mineral wool and wind barrier, and b) mineral wool and OSB/interior sheathing for the reference simulation, the simulation with a foil as wind barrier, and the simulation with a foil as vapour barrier. If condensation occurs, the maximal accumulated condensation $\left(\mathrm{AC}_{\max }\left[\mathrm{kg} / \mathrm{m}^{2}\right]\right)$ on the surface of the foil is mentioned.

\subsubsection{Impact of vapour diffusion resistance}

The previous section showed that interstitial condensation occurs when applying a foil as wind barrier or vapour retarder, yet the maximal amount of accumulated condensation is still acceptable. This section studies the impact of the vapour diffusion resistance of both sheathings on the hygrothermal performance of the wall. Both sheathings are modelled as a foil with no moisture buffer capacity. A fixed $\mathrm{s}_{\mathrm{d}^{-}}$ value of $2 \mathrm{~m}$ for the vapour retarder $\left(\mathrm{s}_{\mathrm{d}, \mathrm{i}}\right)$ is chosen, whereas the vapour diffusion resistance of the wind barrier $\left(\mathrm{s}_{\mathrm{d}, \mathrm{e}}\right)$ is varied in 4 simulations: a ratio of $\mathrm{s}_{\mathrm{d}, \mathrm{i}} / \mathrm{s}_{\mathrm{d}, \mathrm{e}}$ of $1,3,6$, and 15 is applied.

Figure 10 presents the mould growth risk for the top and bottom wooden beam. Similar to the reference case, there is no mould growth risk at the interior side. At the outside, however, a significant difference is observed between the different walls. A higher mould risk is obtained for lower $\mathrm{s}_{\mathrm{d}, \text { in }} / \mathrm{s}_{\mathrm{d} \text {,ext }}$ ratios, yet the mould index for the top wooden beam is higher than 3 for all walls. For the wall in which the ratio is equal to 1 , a significant mould risk for the lower beam is obtained as well. The significant difference between the top and bottom wooden beam shows the ability of cavity ventilation to lower the moisture levels inside the construction, yet the ventilation rate created by $1 \mathrm{OHJ} / \mathrm{m}$ does not suffice to dry out the entire cavity.

Finally, the maximal $\mathrm{RH}$ at the interface between mineral wool and wind barrier/vapour retarder for the different simulations is presented in Figure 11. The difference at the interface between mineral wool and wind barrier is limited, since for this interface the advantage of a rather vapour open, or rather vapour tight wind barrier depends on the season. Due to cavity ventilation, however, the maximal $\mathrm{RH}$ at the bottom of the wall is lower for the more vapour open wind barriers.
On the other hand, the impact of the vapour diffusion resistance on the maximal $\mathrm{RH}$ at the interface between MW and vapour retarder is more straightforward. A wind barrier with a higher vapour diffusion resistance has a significant effect on the RH at this interface. For all simulations, however, the threshold for condensation run-off is not attained, and hence, the risk of wood decay is limited. Note, however, that an sd-value of $2 \mathrm{~m}$, chosen here to correspond to the vapour diffusion resistance of the OSB, is rather low for a foil as vapour retarder. Results might be different when applying a higher sdvalue.

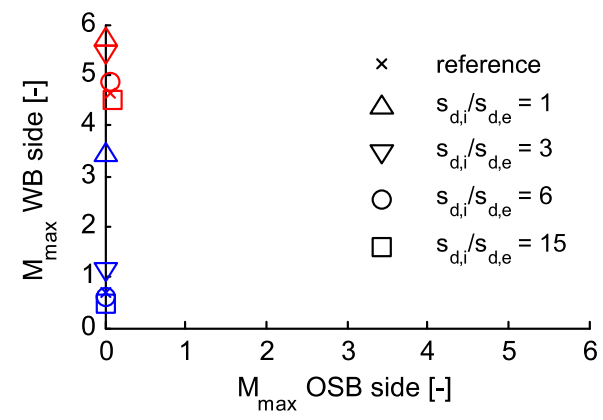

Fig. 10: The maximal mould index for the top (red) and bottom (blue) wooden beam at the side of the wind barrier (WB) and OSB for the simulations with varying $\mathrm{s} d, \mathrm{i}_{\mathrm{d}} / \mathrm{s}_{\mathrm{d}, \mathrm{e}}$ ratio.
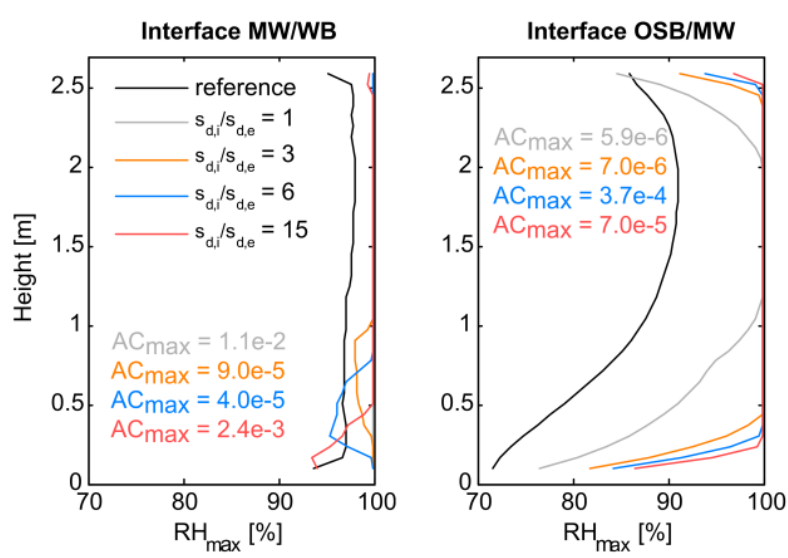

Fig. 11: Maximal RH at the interface between a) mineral wool and wind barrier, and b) mineral wool and OSB/interior sheathing for the reference simulation and the simulations with a varying $\mathrm{sd}, \mathrm{i} / \mathrm{S} d, \mathrm{e}$ ratio. If condensation occurs, the maximal accumulated condensation $\left(\mathrm{AC}_{\max }\left[\mathrm{kg} / \mathrm{m}^{2}\right]\right)$ on the surface of the foil is mentioned.

\subsubsection{Impact of cavity ventilation rate}

The analysis above demonstrated that limit state criteria regarding mould growth on the wooden beam at the top of the wall were not met for quasi all simulations. Moreover, if the timber frame wall is provided with a foil as interior and/or exterior sheathing, interstitial condensation occurs at the considered surface. Therefore, in this section the potential of an increased cavity ventilation rate to improve the overall performance of a timber frame wall with brick veneer cladding is investigated. Compared to the reference simulation, the cavity ventilation rate is multiplied by a factor 2, 10 and 100. The first represents the situation in which $2 \mathrm{OHJ} / \mathrm{m}$ are provided in the brick veneer 
cladding, whereas the latter corresponds to an air change rate in the same order of magnitude as for sidings or rendered systems. For comparison, also a simulation without cavity ventilation is considered.

First, the configuration of the reference wall is considered to investigate the impact of cavity ventilation. Figure 12 presents the mould growth risk inside the construction. Since no higher mould indices at the interface between OSB and mineral wool are obtained, the $\mathrm{x}$-axis is here restricted to a mould index of 1 . The mould growth risk when no cavity ventilation is provided is significantly higher at mid-height for the interface between mineral wool and wind barrier, and for the wooden beam at the bottom of the wall. Hence, although the cavity ventilation rate in case of a brick veneer cladding is relatively low, it is still important to lower the mould growth risk inside the construction. In addition, a further increase in cavity ventilation rate generally leads to a lower mould growth risk. This is not the case, however, for the beam at the bottom of the wall: the mould growth risk is higher for the simulations with a cavity ventilation rate multiplied by a factor 2 and 10. Finally, from these results it can be concluded that providing $2 \mathrm{OHJ} / \mathrm{m}$ is still not sufficient to meet the limit state criterion regarding mould growth. A cavity ventilation rate which is 10 times higher than the one provided by $1 \mathrm{OHJ} / \mathrm{m}$ does. Consequently, using a poorly ventilated cladding like brick veneer instead of a well-ventilated cladding like sidings indeed leads to an increased risk of mould growth inside the timber frame wall. Finally, regarding the maximal RH at the potential condensation planes: even when there is no cavity ventilation, the simulations do not indicate interstitial condensation for the reference simulation.

Section 3.1.1 demonstrated that interstitial condensation occurs if a foil, which has no moisture buffer capacity, is applied as interior and/or exterior sheathing. It is therefore investigated to what extent an increased cavity ventilation rate can avoid condensation to occur in a construction including a foil. The two simulation models from section 3.1.1 in which in one wall a foil was provided as exterior and in the other one as interior sheathing are considered. Figure 13a presents the maximal $\mathrm{RH}$ at the interface between mineral wool and exterior sheathing for the simulation in which the exterior sheathing is a foil, while Figure $13 \mathrm{~b}$ presents the maximal RH at the interface between mineral wool and interior sheathing for the simulation in which the interior sheathing is a foil. Even for both simulations in which the reference cavity ventilation rate is multiplied by 100 , condensation still occurs at the considered interface. However, compared to the simulation with the reference cavity ventilation rate, the condensation rate at the interior sheathing is up to one order of magnitude lower, and at the exterior sheathing up to three orders of magnitude lower. Without cavity ventilation, the accumulated condensation is at least twice as high compared to the simulation with the reference ventilation rate, but the limit state criterion regarding accumulated condensation is still met.
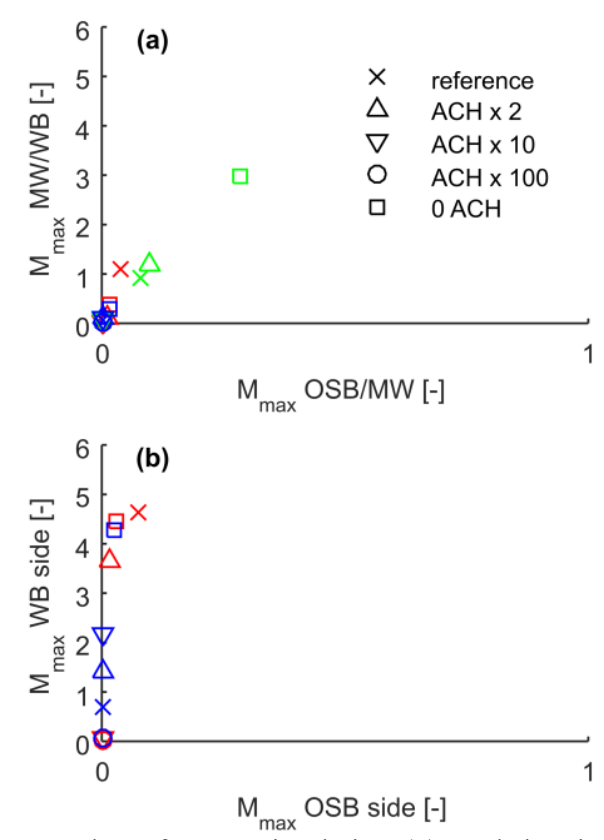

Fig. 12: For the reference simulation (x), and the simulations with a cavity ventilation rate multiplied by $2(\Delta), 10(\nabla), 100$ (o) and $0(\square)$ compared to the reference simulation: a) the maximal mould index at the top (red), middle (green) and bottom (blue) of the interface between mineral wool and inand exterior sheathing; and b) the maximal mould index for the top (red) and bottom (blue) wooden beam at the side of the wind barrier (WB) and OSB.

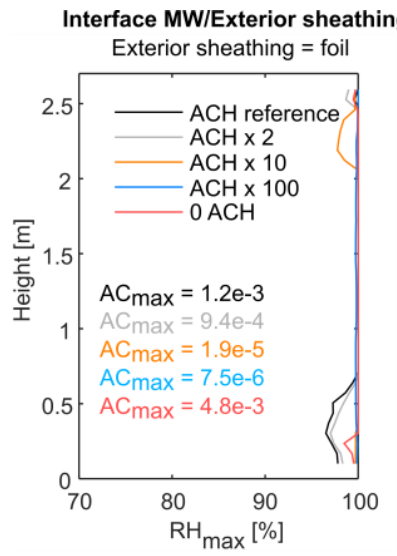

(a)

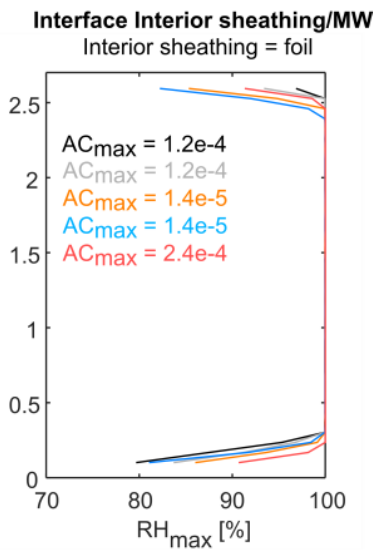

(b)
Fig. 13: The maximal $\mathrm{RH}$ at the interface between a) mineral wool and foil as exterior sheathing, and b) mineral wool and foil as interior sheathing for the simulations with varying cavity ventilation rates.

\section{Conclusion}

This chapter investigated the hygrothermal performance of timber frame walls with a brick veneer cladding. To do so, a field study on two test walls has been conducted, focusing on the role of the vapour diffusion resistance of the wind barrier: a vapour open wind barrier is considered advantageous during an outward vapour flow (i.e. in typical winter conditions for European climates), yet during an inward vapour flow (i.e. in summer conditions) a more vapour tight wind barrier is appropriate. Therefore, one set-up was provided with a vapour open wood fibre board as wind barrier, the other 
set-up with a more vapour tight wood fibre cement board. The data of the in-situ measuring campaign indicated that the differences between both set-ups is rather limited. The relative humidity at the interface between insulation and wind barrier for the vapour open set-up was even regularly higher compared to the vapour tight set-up. This can be explained by the high moisture levels inside the cavity behind the brick veneer cladding. Even in winter conditions, the cavity vapour pressure is often higher than the indoor vapour pressure, which in that case makes a more vapour tight wind barrier more beneficial to reduce the moisture levels at its interface with the insulation layer. Nevertheless, while the maximal $\mathrm{RH}$ at the interface between insulation and wind barrier constantly stayed at or below $95 \%$ for the vapour open set-up, the maximal RH for the vapour tight set-up achieved higher levels during cold periods. Also in summer conditions, the difference between both setups was rather limited. Moreover, despite large vapour pressure differences between cavity and indoor conditions, the $\mathrm{RH}$ at the interface between insulation and vapour retarder hardly exceeded $80 \%$. Main reason might be the buffer capacity in the wall.

In addition, a parameter analysis based on numerical simulations have been conducted to

The final part of this paper provided a deterministic parameter study to assess the impact of the material properties of the in- and exterior sheathing and cavity ventilation. A typical timber frame wall with brick veneer cladding was considered as reference simulation, in which the open wind barrier was applied as outer sheathing. The parameter analysis showed for quasi all simulations a significant mould risk for the wooden beam at the top of the wall, more specifically the part close to the wind barrier. In contrast, no mould growth was predicted for the wooden beam at the bottom of the wall, caused by the dominant upward direction of buoyancy driven cavity ventilation flow. Consequently, cavity ventilation created by $1 \mathrm{OHJ} / \mathrm{m}$ clearly does not suffice to avoid mould growth for the entire construction. It was shown that the mould risk was eliminated when a cavity ventilation rate in the same order of magnitude as the one for sidings or rendered systems was imposed. Furthermore, providing a foil as interior or exterior sheathing leads to interstitial condensation at the interface with the mineral wool insulation layer, and hence an increased risk of wood decay for the wooden elements at the bottom of the wall. Yet, run-off conditions were not attained in the current study. Nevertheless, applying materials with a hygroscopic moisture buffer capacity as interior or exterior sheathing leads to a significant better hygrothermal performance of the wall. Alternatively, applying an insulation layer at the exterior side of the wind barrier might avoid condensation at the wind barrier in winter conditions as well.

The research presented in this paper is part of research project 3E140592 funded by the Fonds voor Wetenschappelijk Onderzoek - Vlaanderen (FWO): 'A stochastic and dynamic risk assessment methodology for mould growth and wood rot on timber frame constructions.'

\section{References}

1. J. Vinha, P. Käkelä, Water vapour transmission in wall structures due to diffusion and convection, Tampere, Finland, 1999.

2. BBRI, Vochtbeheersing bij houtbouw, 2013/01.04 (2013).

3. D. Derome, S. Saneinejad, Build. Environ. 45 (2010) 2790-2797.

4. A. Tenwolde, H.T. Mei, ASHRAE/DOE/BTECC Therm. Perform. Exter. Envel. Build. III. (1985).

5. J. Langmans, T.Z. Desta, L. Alderweireldt, S. Roels, Build. Environ. 95 (2016) 1-12.

6. M. Vanpachtenbeke, J. Langmans, J. Van Den Bulcke, J. Van Acker, S. Roels, Energy Procedia, 2017: pp. 363-368.

7. M. Vanpachtenbeke, J. Langmans, J. Van den Bulcke, J. Van Acker, S. Roels, Proc. 7th Int. Build. Phys. Conf. IBPC, Syracuse, New York, 2018: pp. 235-240.

8. S. Roels, VLIET test-building KU Leuven, in: A. Janssens, S. Roels, L. Vandaele (Eds.), Full Scale Test Facil. Eval. Energy Hygrothermal Perform., 2011.

9. M. Vanpachtenbeke, Timber frame walls with brick veneer cladding: reliability to fungal decay, KU Leuven, Belgium, 2019. PhD thesis.

10. J. Grunewald, Diffusiver und konvektiver Stoffund Energie- transport in kapillarporösen Baustoffen, University of Technology Dresden, 1997.

11. A. Nicolai, Modeling and Numerical Simulation of Salt Transport and Phase Transitions in Unsaturated Porous Building Materials, Syracuse University, 2007.

12. T. Ojanen, H. Viitanen, R. Peuhkuri, K. Lähdesmäki, J. Vinha, K. Salminen, Therm. Perform. Exter. Envel. Whole Build. XI Int. Conf., 2010.

13. J. Langmans, Feasibility of Exterior Air Barriers in Timber Frame Constructions, KU Leuven, 2013. $\mathrm{PhD}$ thesis.

14. A. Janssens, Reliable Control of interstitial condensation in lightweight roof systems. Calculation and assessment methods, KU Leuven, 1998. PhD thesis. 